\title{
Nadir Görülen Bronş Basısı Nedeni: Hafif Pulmoner Hipertansiyon
}

\section{A Rare Cause of Bronchial Compression: Mild Pulmonary Hypertension}

\author{
Şahin SINCAR¹, Emine AKKUZU11, Gökhan KALKAN¹, Semiha TERLEMEZ TOKGÖZ², \\ Fatma HAYVACI CANBEYLi²
}

${ }^{1}$ Gazi üniversitesi Tıp Fakültesi, Çocuk Sağlığı Hastalıkları AnabilimDalı, Çocuk Yoğun Bakım Bilim Dalı, Ankara

${ }^{2}$ Gazi üniversitesi Tıp Fakültesi, Çocuk Sağlı̆ı̆ Hastalıkları AnabilimDalı, Çocuk Kardiyoloji Bilim Dalı, Ankara

\begin{abstract}
öz
Atriyal septal defekt (ASD) ve ventriküler septal defekt (VSD) en sık görülen konjenital kalp anomalileridir. Bu olgu sunumunda ASD ve VSD'ye ikincil gelișen hafif pulmoner arteryel hipertansiyonla (PAH) birlikte seyreden, solunum ve böbrek yetmezliği nedeniyle entübe edilmiş olan altı aylık kız hasta takdim edilmiștir. Ekstübasyon başarısızlığına neden olan sol total atelektazinin sık tekrar etmesi nedeniyle hasta bronş basısı açısından incelendiğinde sağ pulmoner arterin (PA) sol ana bronşa kompresyonu tespit edilmiștir. Aynı seansta ASD ve VSD'nin de kapatılı̆̆ı operasyonda sağ PA çıkan aort önüne askıya alınarak bası giderilmiştir. Ameliyat sonrası başarılı bir şekilde ekstübe edilen hasta şifa ile taburcu edilmiștir. Özellikle konjenital kalp hastalığı olan ve aynı lokalizasyonda ortaya çıkan, tekrar eden pulmoner atelektazi olgularında bronş basısı öncelikle düşünülmesi gereken etiyolojilerden birisidir.
\end{abstract}

Anahtar Sözcükler: Atelektazi, Bronş, Bası, Pulmoner hipertansiyon

\begin{abstract}
Atrial septal defect (ASD) and ventricular septal defect (VSD) are the most common congenital heart anomalies. In this case report, a six-month-old girl with mild pulmonary arterial hypertension (PAH) secondary to ASD and VSD was presented. The patient was admitted due to respiratory failure and renal insufficiency. Evaluation for recurrent extubation failures secondary to left total atelectasis yielded right pulmonary arterial (PA) compression to the left main bronchus. Compression was relieved with right pulmonary arteriopexy with ASD and VSD closure in the same session. The patient was extubated successfully in the immediate postoperative period and eventually discharged home. Bronchial compression should be considered especially in patients with congenital heart disease and recurrent cases of atelectasis in the same location.
\end{abstract}

Key Words: Atelectasis, Bronchial, Compression, Pulmonary hypertension

\section{GiRiş}

Atriyal septal defekt (ASD) ve ventriküler septal defekt (VSD) en sık görülen konjenital kalp anomalileridir (1). Pulmoner arteryel hipertansiyon $(\mathrm{PAH})$ yaygın olarak $\mathrm{ASD}, \mathrm{VSD}$, patent duktus arteriosus gibi konjenital kalp hastalıkları ile ilişkilidir. VSD, ASD erken yaşta kapatımadığı takdirde soldan sağa şanta bağı artmış kan akımı ilişkili PAH'a neden olur (2). Normal şartlarda hafif ve orta derecedeki PAH'da çevre anatomik yapılara bir bası söz konusu değilken, anatomik varyasyon varlığında hafif derecedeki PAH dahi çevre dokulara bası yapabilir. Bronşlar anatomik olarak PA yakın ilişki içindedir. Dolayısıyla bu gibi durumlarda bronş basısına bağlı hayatı tehdit edici bulgular ortaya çıkabilir. Pulmoner arterlerin bronşlara bası yapması akciğerlerin tamamen veya kısmi olarak kapanmasına neden olur. Burada tekrarlayan entübasyon nedeni olarak PA'nın bronşa basısı ve bunun neden olduğu sol akciğer total atelektazisi ile tanı koyulan 6 ayllk kız hasta sunulmuştur.
Yazışma Adresi / Correspondence Address:

Şahin SiNCAR

Gazi üniversitesi Tıp Fakültesi,

Çocuk Sağlığı Hastalıkları AnabilimDalı, Çocuk Yoğun Bakım Bilim Dalı, Ankara,Türkiye

E-posta: sahinsincar@hotmail.com
Geliş tarihi / Received : 03.10.2018

Kabul tarihi / Accepted : 14.12.2018

Elektronik yayın tarihi : : 10.05.2019

Online published

DOI: 10.12956/tchd.562719 


\section{OLGU}

Altı aylık ASD ve VSD ile takipli ve daha öncesinde solunum sistemi ile ilgili bir sıkıntısı olmadığı belirtilen kız hasta 1 ay önce, yaklaşık 1 haftadır, günde 3-4 kez olan kusma şikayetiyle mahallinde devlet hastanesine başvurmuş. Dehidrate görünen hastanın kandan bakılan tetkiklerinde üre:155 (mg/dL), kreatinin: 3.7 (mg/dL), gelmesi üzerine akut böbrek yetmezliği tanısıyla Ankara'da bir eğitim ve araştırma hastanesine sevk edilmiş. Dış merkez yatışında idrar yolu enfeksiyonu tanısıyla seftriakson tedavisi başlanan, ödem nedeniyle diüretik tedavisi verilen hastanın yatışının 3.gününde solunum yetmezliği tanısıyla çocuk yoğun bakıma alınmış ve entübe edilerek konvansiyonel mekanik ventilatörde izlenmiş. Bir aylık yoğun bakım yatışı sırasında 4 kez ekstübasyon denenmiş ve ekstübasyondan 8-10 saat sonra solunum yetmezliği tablosunda tekrar entübe edilmiş. Ekstübasyonu tolere edemeyen hasta 112 aracılığıyla çocuk yoğun bakım ünitemize devralındı.

Entübe ve mekanik ventilatörde kabul edilen hastanın fizik muayenesinde genel durumu orta-kötüydü, tüm vücudunda yaygın ödem mevcuttu, sol akciğerinde solunum sesi yoktu, apekste 4/6 sistolik üfürüm mevcuttu ve karaciğer kot altı midklaviküler hatta $3 \mathrm{~cm}$ ele geliyordu. Posteroanterior akciğer grafisinde (PAAG) pulmoner konus belirgin, sol akciğerin tamamen kollabe olduğu görüldü (Şekil 1). Ekokardiyografisinde EKO'da sekundum ASD, subaortik outlet VSD, ana PA ve sağ dalda belirgin olmak üzere PA dallarında genişleme olduğu görüldü. Hastaya akut böbrek yetmezliği ve buna ikincil gelişen sıvı yüküne yönelik yüksek dozlarda furosemid infüzyonu verildi. Günlük aldığı çıkardığı sıvı takibi yapılarak ödemi kademeli olarak azaltıldı. Bize başvurusunda kreatinin değeri $1.5 \mathrm{gr} / \mathrm{dl}$ civarı iken zamanla düşerek yaşına göre bazal değerlere indi. Uzun süreli entübasyon öyküsü, ateşi ve akut faz reaktanlarında yükseklik

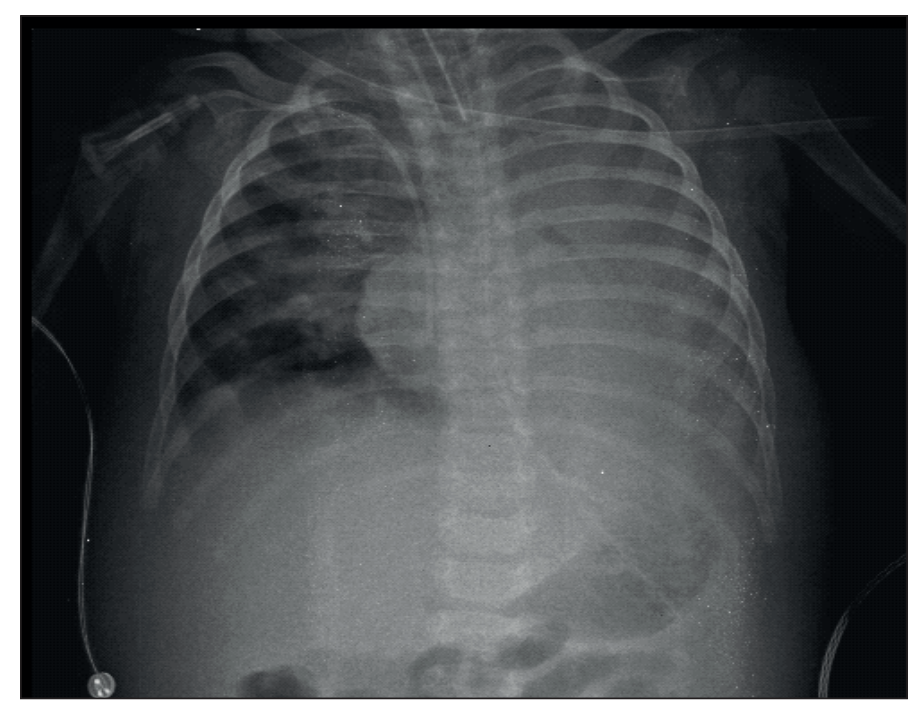

Şekil 1: PAAG; Sol akciğer total atelektazik (ilk geliş 1.saatte çekilen). olması nedeniyle geniş spektrumlu antibiyotik tedavisi verildi. Ödemi ve PAAG'sinde atelektazisi belirgin gerileyen, bazal ventilatör ayarlarıla solutulan hastaya gelişinin 24. Saatinde ekstübasyon denendi. Ekstübasyonun ilk saatlerinde atelektazi gelişmeyen hastada 8-10 saat sonra sol total atelektaziye bağlı solunum yetmezliği gelişti. Bunun üzerine hasta tekrar entübe edildi. Entübasyonla atelektazinin gerilediği görüldü. Hastaya atelektazisine neden olabilecek mukus tıkacı açısından etkin göğüs fizyoterapisi verildi. Bu şekilde tekrar ekstübasyon denemelerinde de aynı sol total atelektazi gelişmesi nedeniyle hastaya muhtemel bronş basısına yönelik kontrastlı toraks bilgisayarlı tomografisi (BT) ve BT anjiografi çekildi. BT'de sol ana bronşun 2 cm'lik segmentine karina sonrası sağ PA basısı mevcuttu ve sol ana bronş bifürkasyon düzeyinden itibaren inen aorta anterior komşuluğuna kadar (basıya ikincil) izlenemedi, buna bağlı olarak sol akciğerin total olarak atelektatik olduğu, havalanmadığı görüldü (Şekil 2). Yapılan ölçümde ana PA çapı:20 mm (z skoru: 5), sağ PA çapı:17 mm (z skoru: 4.7), sol PA çapı 15.5 mm (z skoru: 4.1) olarak saptandı. Hastaya bronkoskopi planlanmıştı ancak BT sonucunda etiyoloji aydınlatıınca buna gerek duyulmadı. Kardiyak kateterizasyon ile soldan sağa şant olduğu görüldü, PA basıncı 42 (65/17) mmHg olarak ölçüldü, ostium sekundum tipi ASD, subaortik outlet VSD ve PA'de dilatasyon gösterildi. Hasta çocuk kardiyoloji, çocuk göğüs hastalıkları, çocuk yoğun bakım ve kalp damar cerrahisinin katıımıyla konseyde tartışıldı ve hastanın yaşı itibariyle hem ASD, VSD için primer onarım hem de sağ PA basısının sol ana bronş üzerinden kaldırılmasına yönelik cerrahi yapılmasına karar verildi.

Hasta kabulünün 14. gününde operasyona alındı. Operasyonda ASD ve VSD kapatıldı, sağ PA aortanın ön tarafına alınarak ana PA'e anastomoz edildi. Postoperatif yoğun bakıma alınan hasta konvansiyonel mekanik ventilatörde entübe takip edildi. Ameliyat

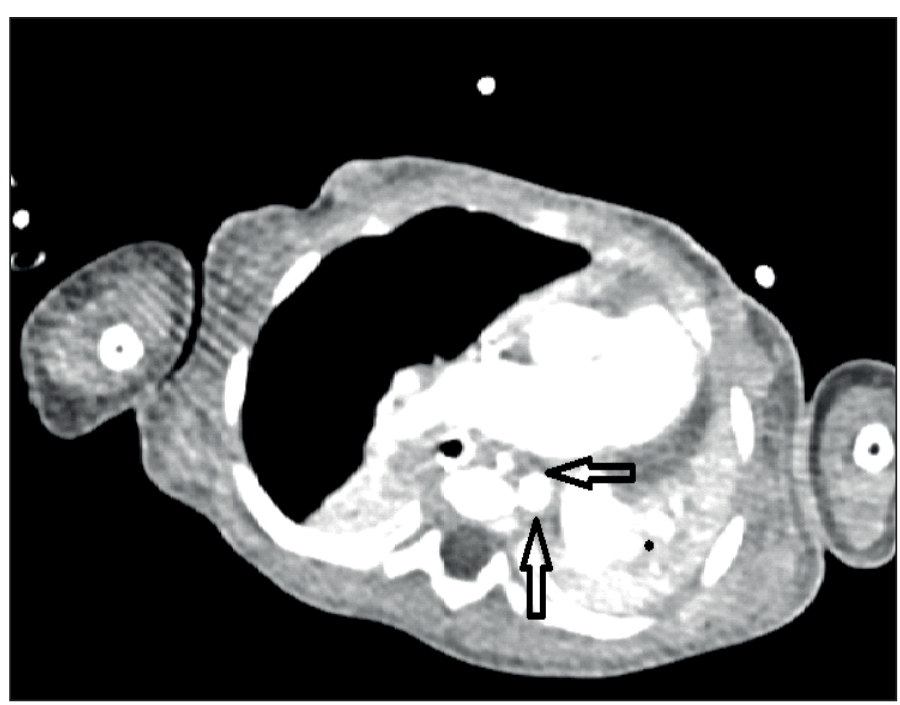

Şekil 2: Toraks BT: Sağ pulmoner arterin sol ana bronşa basısı ve total kollabe olmuş sol akciğer (Yatay ok sol ana bronşu, dikey ok sağ pulmoner arteri göstermektedir). 


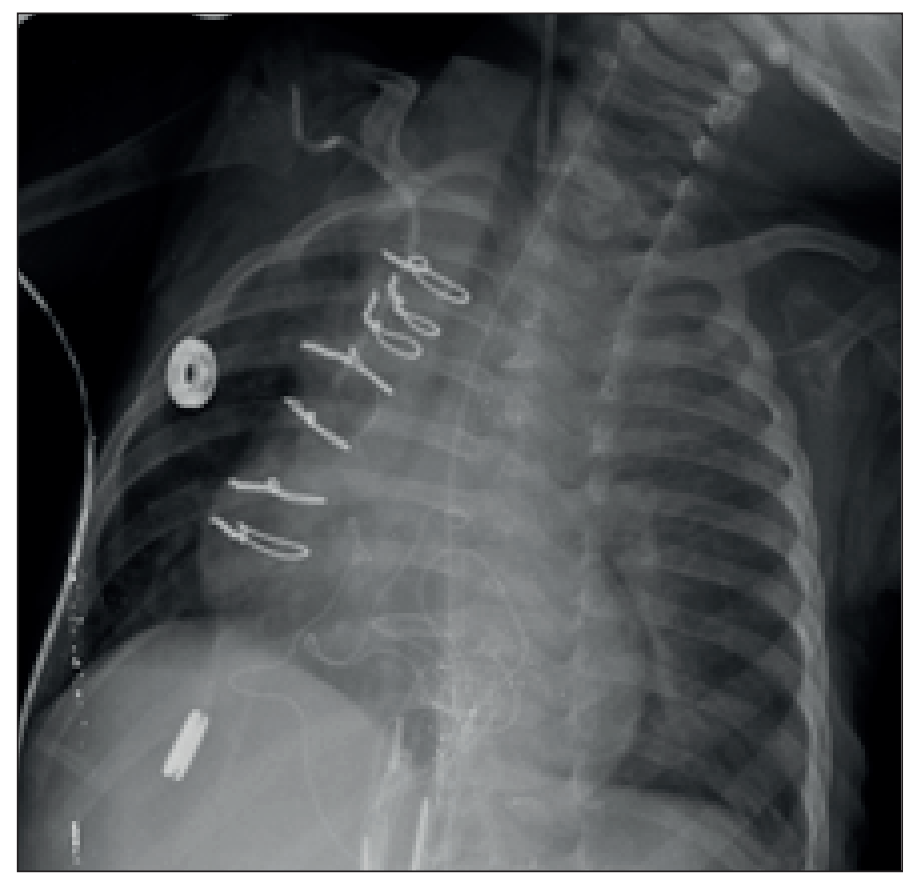

Şekil 3: Ameliyat sonrası akciğer grafisi

sonrası PAAG'de sol akciğerin tamamen açıldığı görüldü (Şekil 3). Hastanın bakılan ekokardiyografisinde ortalama PA basıncı 20 mmHg saptandı, ASD ve VSD'ye ait rezidü saptanmadı. Ameliyat sonrası 3.günde hastada akut hipoksi ve eş zamanlı hemoglobin düşüklüğü gelişmesi sonrası kalp damar cerrahisinin önerisiyle de kanama açısından çekilen kontrol kontrastı toraks BT anjiografisinde sol ana bronşta eski incelemede izlenen PA bronş basısı bu incelemede izlenmedi (Şekil 4). Ayrıca hipoksi ve hemoglobin düşüklüğünü açıklayacak bir patoloji saptanmadı. Hastanın kliniği ek müdahale gerektirmeden kendiliğinden toparladı. Hastada iki defa kontrastlı BT çekilmesi nedeniyle böbrek koruyucu n-asetil sistein protokolü verildi. İleminde mekanik ventilatör ayarları kademeli olarak azaltılan hasta ameliyat sonrası 7. günde ekstübe edildi. Klinik izleminde vital bulguları stabil seyreden hasta 9.günde servise devredildi.

\section{TARTIȘMA}

Çocuklarda atelektazi bașlıca obstrüktif, resorbtif, relaksasyon ve kompresif atelektazisi olmak üzere bașlıca dört tiptir ve en sık görülen tipi obstrüktif atelektazidir $(1,2)$. Obstrüktif tip tam veya kısmi hava yolu tıkanıklığına bağlı olarak oluşur. Obstrüktif atelektazi anatomik lokalizasyonuna göre intraluminal ve ekstramural olarak ayrıca sınıflandırılabilir. Atelektazinin intraluminal nedenlerinin örnekleri arasında hava yolunda yabancı cisim, kan pıhtısı, mukus tıkacı ve tümör sayılabilir. Ekstramural bronș basısı atelektaziye neden olabilir. Basıya birçok anatomik yapı yol açsa da (kitle, apse, hematom vs.) pediatrik yaş grubunda vasküler anomaliler önemli yer tutar

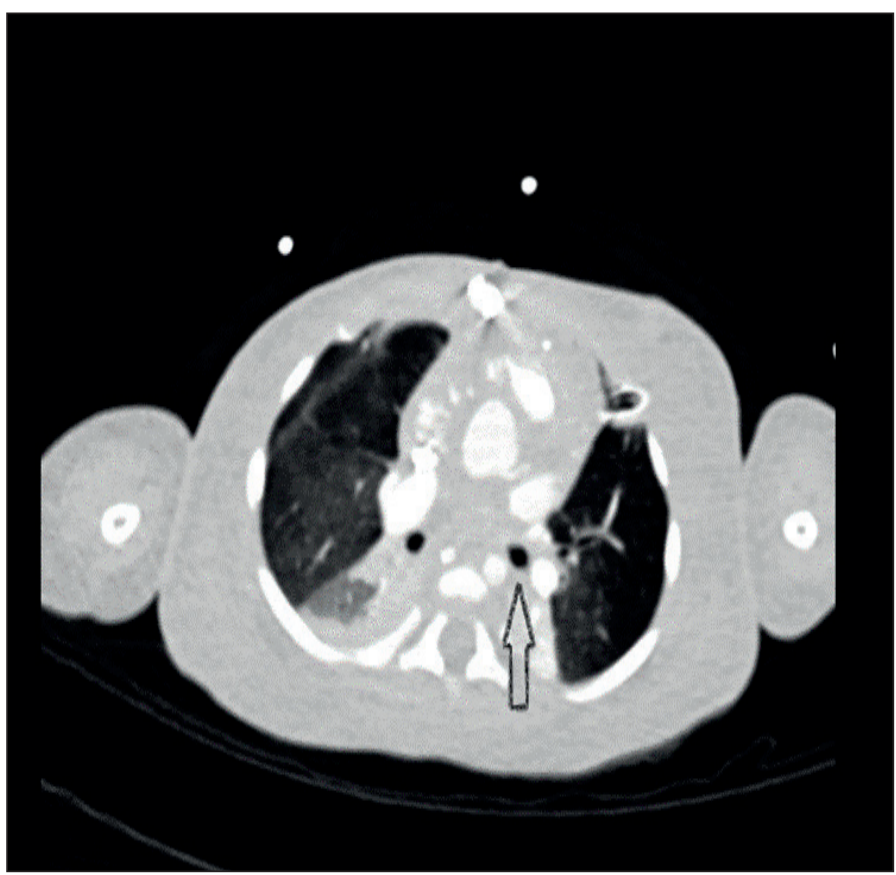

Şekil 4: Ameliyattan sonraki toraks BT görüntüsü; sol ana bronş basısının gerilediği ve aortun önündeki sağ pulmoner arter görülmektedir (Ok, solda basıdan kurtulmuş ana bronşu göstermektedir).

(3-5). Olgumuzda da bronş basısına ASD ile VSD'ye sekonder gelişen pulmoner hipertansiyon ve PA dilatasyonu neden olmuştur.

Konjenital kalp hastalıklarının bir kısmında klinik olarak anlamlı PAH gelişebilmektedir. Tanım olarak PAH; büyüklüğü ve konumu nedeniyle, pulmoner dolaşımın sistemik düzeydeki arteriyel basınca maruz kaldığı durumda ortaya çıkar. Büyük VSD'ler bunun en yaygın örneğidir. Bunların zamanında onarılması bu açıdan büyük önem taşımaktadır. ASD’ler düşük basınçlı şant ile ilişkili olup çocukluk çağında çok seyrek olarak PAH'a yol açarlar; PAH geliștiği zaman, genellikle yașamın ilk yirmi yılından sonra ortaya çıkar (6).

Pulmoner Arterlerin hava yoluna basısı, siyanotik veya asiyanotik konjenital kalp hastalıklarıyla beraber görülebilir. Sık solunum yolu enfeksiyonu, wheezing, pnömoni, atelektazi ve havalanma artışı ile klinik bulgu verebilir. Normal şartlarda hafif ve orta derecedeki PAH'da çevre anatomik yapılara bir bası söz konusu değilken, anatomik varyasyon varlığında hafif derecedeki PAH dahi çevre dokulara bası yapabilir. Bronşlar anatomik olarak PA'le yakın ilişki içindedir. Dolayısıyla, bu gibi durumlarda bronş basısına bağlı hayatı tehdit edici bulgular ortaya çıkabilir. PA'lerin bronşa yakın olması nedeniyle, pulmoner hipertansiyonun bronş basısına neden olması durumunda PA'de dilatasyon da beklenen bir bulgudur. PA'de dilatasyon çeşitli yerlerde hava yolu basısına neden olabilir; en yaygın olanı sol ana bronşun üst yönüdür; diğer bölgeler genellikle sağ PA'in sağ orta lob bronşu ile birleşim yeridir (7-9). Trakeobronşial bası ilişkili kardiyak defektlerde ekokardiyografi, toraks BT ve bronkoskopi ile kesin anatomik tanımlama ve cerrahi planlama yapılması tanı ve tedavi 
sürecinde önemli rol oynar (8). Hastamıza da bronkoskopi planlanmıştı ancak BT sonucunda sol ana bronşa PA basısı saptanması üzerine buna gerek duyulmadı. Pulmoner anjiyografi önceleri tanıda altın standart olarak kabul edilmiş olsada, günümüzde non-invazif üç boyutlu görüntüleme yöntemleri de, anatomi hakkında yeterli bilgi vermektedir. Bu vakada olduğu gibi kardiyak defektle birlikte olan bası patolojilerinde ameliyatın amacı, kalp defektini, PA'lerin neden olduğu, hava yollarının dekompresyonuyla birlikte onarımasıdır. Bu olgularda, sağ PA'in mevcut lokalizasyonundan ön tarafa asılması veya intrakardiyak tamir ile birlikte trakeoplasti ile hava yolu rahatlaması hava yolu kompresyonunu hafifletmekte başarılı olmuştur $(2,10,11)$.

Sonuç olarak özellikle konjenital kalp hastalığı olan çocuklarda ekstübe edilememe nedeni olarak lokalize tekrarlayan atelektazi vakalarında bronş basısı ilk hatırlanması gereken etiyolojik faktörlerden birisidir. Konjenital kalp hastalığı olan hastalarda bronş basısı tespit edildiği takdirde vasküler anomaliler açısından ayrıntılı değerlendirme yapılmalıdır.

Çelişkili Çıkarların Beyanı: Yazar, bu makalenin araştıııması, yazarlığı ve yayına ilişkin herhangi bir çıkar çatışması olmadığını beyan etmiştir.

Finansman: Yazarlar bu makalenin araştırılması, yazarlığı veya yayımı için mali destek almadı.

\section{KAYNAKLAR:}

1. Wallis C, McLaren CA. Tracheobronchial stenting for airway malacia. Paediatr Respir Rev 2018;27:48-59.

2. Talwar S, Sharma P, Choudhary SK, Kothari SS, Gulati GS, Airan B. Le-Compte's maneuver for relief of bronchial compression in atrial septal defect. J Card Surg 2011;26:111-3.
3. Eugene Blackstone, Frank Hanley, James Kirklin, Nicholas Kouchoukos. Atrial septal defect and partial anomalous pulmonary venous connection. Kirklin Barratt Boyes Cardiac Surgery. Elsevier Saunders; 4nd ed. Philadelphia 2013:1156.

4. Kussman BD, Geva T, Mcgowan FX Jr. Cardiovascular causes of airway compression. Pediatr Anesth 2004;14: 60-74.

5. Eyüboğlu TŞ, Aslan AT, Öztunalı Ç, Tunaoğlu S, Oğuz AD, Kula $S$, et. al Unknown vascular compression of the airway in patients with congenital heart disease and persistent lower respiratory symptoms, Turk J Med Sci 2017;13:1384-92

6. Berlinger NT, Long C, Foker J, Lucas RV Jr. Tracheobronchial compression in acyanotic congenital heart disease. Ann Otol Rhinol Laryngol 1983;92:387-90.

7. Stanger P, Lucas RV Jr, Edwards JE. Anatomic factors causing respiratory distress in acyanotic congenital cardiac disease. Special reference to bronchial obstruction. Pediatrics 1969;43:760-9.

8. Kulik TJ .Department of Cardiology, Division of Cardiac Critical Care, and the Pulmonary Hypertension Program, Children's Hospital Boston, Boston, Massachusetts, USA. Pulm Circ 2012;2:327.

9. Hraska V, Photiadis J, Schindler E, Sinzobahamvya N,Fink C,Haun C, et al. A novel approach to the repair of tetralogy of Fallot with absent pulmonary valve and the reduction of airway compression by the pulmonary artery. Semin Thorac Cardiovasc Surg Pediatr Card Surg Annu 2009;12:59-62.

10. Nomura N, Asano M, Mizuno A, Mishima A. Translocation of dilated pulmonary artery for relief of bronchial compression associated with ventricular septal defect. Eur J Cardiothorac Surg 2007;32:937-9.

11. Zopf DA, Hollister SJ, Nelson ME, Ohye RG, Green GE. Bioresorbable Airway Splint Created with a Three-Dimensional Printer. N Engl J Med 2013;21:2043-5. 